\title{
New Green Soft Chemistry Route to Ag-Cu Bimetallic Nanomaterials
}

\author{
Xin Liu, Yi Wu, Guiqi Xie, Zirun Wang, Yuan Li and Qing $\mathrm{Li}^{*}$ \\ Faculty of Materials \& Energy, Southwest University, Chongqing 400715, P.R. China \\ *E-mail: qli@swu.edu.cn
}

doi: $10.20964 / 2017.04 .61$

Received: 31 January 2017 / Accepted: 28 February 2017 / Published: 12 March 2017

\begin{abstract}
$\mathrm{Ag}-\mathrm{Cu}$ bimetallic nanomaterials were synthesized by an environmental-friendly liquid phase reduction method with sodium hypophosphite reducing the mixed aqueous solution of cupric acetate silver nitrate and sodium hexametaphosphate. Nitric acid was used to adjust the $\mathrm{pH}$ and sodium hexametaphosphate performed as the surfactant. The $\mathrm{Ag}-\mathrm{Cu}$ bimetallic nanomaterials were characterized with powder X-ray diffraction (XRD), field emission scanning electron microscope (FESEM) and X-ray spectroscopy (EDS). The result showed that $\mathrm{Ag}$ and $\mathrm{Cu}$ are not mechanical mixing but the combination at the atom scale and lattice level. The reaction parameters such as the molar ratio of $\mathrm{Ag} / \mathrm{Cu}$, reaction time and temperature were investigated. The ultraviolet-visible absorption spectra (UV-vis) and electrochemical properties of the samples were explored and it was found that the sample shown high electrochemical activity and excellent performance of hydrogen evolution.
\end{abstract}

Keywords: Ag-Cu bimetallic, Soft chemistry, Electrochemical property

\section{FULL TEXT}

(C) 2017 The Authors. Published by ESG (www.electrochemsci.org). This article is an open access article distributed under the terms and conditions of the Creative Commons Attribution license (http://creativecommons.org/licenses/by/4.0/). 